\title{
Probe P3 and blinks: Two measures of affective startle modulation
}

\author{
HARALD T. SCHUPP, a,b BRUCE N. CUTHBERT, ${ }^{a}$ MARGARET M. BRADLEY,a \\ NIELS BIRBAUMER, ${ }^{b}$ AND PETER J. LANG ${ }^{a}$ \\ University of Florida, Gainesville, USA \\ 'University of Tübingen, Tübingen, Germany
}

\begin{abstract}
Two concurrent measures of the evoked startle response, the elicited blink reflex and the event-related potential, were measured while individuals viewed pictures that varied in pleasure and arousal. Replicating previous findings, the blink response was modulated by picture pleasantness, with larger reflexes elicited in the context of viewsmaller P3 responses elicited pictures. However, the probe P3 was primarily modulated by picture arousal, with smaller P3 responses elicited when viewing affective (pleasant or unpleasant) than when viewing neutral pictures. suggest that two measurable responses for probes presented in a subsequent picture imagery period. These data with blink mante startle probe are differentially modified by emotional context, with blink magnitude varying with pleasure and probe P3 varying with stimulus arousal.
\end{abstract}

Descriptors: Event-related potentials, P3, Startle, Emotion, Attention, Arousal

The use of a startle probe in the study of emotion has been encouraged in recent years by the reliable finding that the blink component of the startle reflex is potentiated when individuals view pictures that are unpleasant versus pleasant in affective valence (for an overview, see Lang, Bradley, \& Cuthbert, 1990). Affective modulation of the startle blink has been interpreted as reflecting motivational priming, in which a defensive reflex such as the startle is augmented when the ongoing motivational state is aversive in nature (Lang, 1995). Recent data indicate that these priming effects are largest when the picture stimuli are rated as highly arousing (Cuthbert, Bradley, \& Lang, 1996), suggesting that reflex modulation is strongest when the motivational system is more fully engaged.

The presentation of an intense, abrupt stimulus such as a startle probe elicits responses other than the reflexive eyeblink. Among them is a pronounced P3 wave of the event-related potential (ERP) (Ford \& Pfefferbaum, 1991; Putnam \& Roth, 1990; Roth, Dorato, \& Kopell, 1984; Sugawara, Sadeghpour, DeTraversay, \& Ornitz, 1994). Although the P3 wave is oblig-

This work was supported in part by National Institute of Mental Health grants MH37757, MH41950, MH43975, and MH52384 and National Institute of Aging grant AG09779 10 Peter I. Lang, by the Deutsche Forschungsgemeinschati (SFB 307, B1), and by a grant from the Deutsche Akademische Auslandsdienst to Harald Schupp. We thank Rob Bruner and Mark .Mc.Manis for their assistance in data collection.

These data were presented in part as a poster at the j3rd convention of the Socie:y for Psychophysiological Research in Rottach, Eyern (Schupp. Curthert. Bradley, Lang, \& Birbaumer. 1993)

Address reorint requests to: Bruce Cuthbert. VilhH Center tor the Study oi Emotion and Attention (CSEA), Box 100165 HSC. Gainesviile.
FL $32610-010$. LSA. atory, occurring in the absence of an explicit task instruction, it is modulated by task parameters. For example, Roth et al. (1984) examined startle ERPs when the probe prompted no explicit task, required a button press, or was presented in the context of another (primary) task. Consistent with the hypothesis that the probe $\mathrm{P} 3$ response reflects attentional requirements, the response was reduced when the individual performed a distracting foreground task compared with responses measured in the context of the reaction time task or the passive condition, which did not differ from each other.

To date, we have focused on the blink component of the starthe reflex as it varies with the pleasantness of an affective foreground (e.g., Bradley, Cuthbert, \& Lang, 1990). The goal of the current study was to investigate modulation of the corresponding P3 wave evoked by the startle probe because it may also vary in this affective context. Acoustic startle probes were presented while the individual viewed a subset of pictures selected from the International Affective Picture System (IAPS) (Center for the Study of Emotion and Attention. 1995), a standardized set of emotional stimuli that vary widely on dimensions of pleasure and arousal. The individual's task was to view the pictures and to ignore any occasional noises (startle probes) that were presented.

If probe $\mathrm{P} 3$ responses are modulated similarly to the blink component of the elicited retlex, both measures should vary with the pleasantness (i.e., affective valence) of the foreground picture. However, P3 may vary with the metabolic arousal or activation prompted by the stimulus, independent of its valence. Supporting this hyporhesis is the lac: that reports of arousal seem to index a more general, affective engagement with the stimulus. That is, both pleasant and unpleasant picures are con- 
sistently rated higher in arousal, are attended to longer in a freeviewing context, and prompt greater skin conductance change than do neutral pictures (Lang, Greenwald, Bradley, \& Hamm, 1993). If probe P3 reactions vary primarily with nonspecific affective engagement, a significant difference is anticipated between neutral pictures and both classes (pleasant and unpleasant) of emotional pictures.

Blink magnitude and $\mathrm{P} 3$ responses to probes presented in a postpresentation picture imagery period were also measured to determine if affective modulation of the startle response is sustained in the absence of an explicit perceptual context. In this task, the individual was simply instructed to imagine that the picture was still being viewed on the screen for a 6-5 period immediately following picture offset.

\section{Method}

\section{Participants}

Thirty-seven volunteers ( 14 women, 23 men) from the University of Florida introductory psychology course participated as part of class requirement. The data from two participants were omitted from analyses because of computer failure.

\section{Stimulus Materials}

Fifty-four color slides were chosen from the IAPS ${ }^{\prime}$ (Center for the Study of Emotion and Attention, 1995), depicting 18 unpleasant events (e.g., snakes, mutilations, etc.), 18 pleasant events (e.g., sports, opposite sex nudes, etc.), and 18 neutral events (e.g., neutral faces, household objects, etc.). Three orders of slide presentation were arranged such that, across participants, a particular picture occurred in the first, second, or third block, with each block containing six pleasant, six neutral, and six unpleasant slides. In addition, slide order was changed within a block to control local order effects. The computer version of the Self-Assessment Manikin (SAM) was used to obtain subjective ratings of valence and arousal for each picture using a scale ranging from 0 to 20 (Lang, 1980). ${ }^{2}$

The acoustic startle stimulus consisted of a 50 -ms presentation of a $95-d B(A)$ burst of white noise with instantaneous rise time. Startle probes were presented binaurally through matched Telephonics stereo headphones. For each processing period (picture and postpicture), 27 startle probes were delivered at a random time point 2.5-5 s after the beginning of each period, 9 at each of the three valence levels. At each valence, startles were delivered in both periods in 4 trials, in neither period in 4 other trials, and in either picture or postpicture periods (five each) for the remaining 10 trials. Nine startle stimuli were also delivered during the intertrial interval.

'The IAPS slide numbers were as follows: pleasant: 160, 208, 225 , $418,+21,425,429,431,47,450,452,455,49,465.466,468,720,733$. 73. \$03. S08, $\$ 20,851$; neutral: 219. 220, $5 \leq 0,-00,701,702,70 \leq, 708$. -09, 710,715,715,716,717,718,750,755,770: and negative: 107, 109. $112.130,212.300,301,310,313.315,353,602,619,620,623,637,904$. 949. The LAPS and technical manuals can be obtained from Peter J. Lang, VIMH Center for the Study of Emotion and Altention. Box 100165 HSC. Universiry of Florida. Gainesville. FL 32610.

- Ratings were concordant with the a priori grouping, with large difterences in rated pleasantness for pleasant (16.0), neutral (10.7), and unpleasant material (5.9). Ratings of arousal were hign for positive and negative contents $(1+.+$ and $1+.5)$ and much lower for neutral contents (6.4).

\section{Procedure}

After arrival at the laboratory, participants read and signed an informed consent form and filled out several questionnaires. After attachment of electrodes, participants were familiarized with the SAM procedure. They were told that a series of slides would be presented and that each picture should be viewed the entire time it was on the screen. To promote a common mental set for all participants in the postpicture imagery period, they were instructed to imagine that they were still watching the slide, continuing to keep eyes open and fixated on the center of the screen. Both the picture and postpicture imagery periods were $6 \mathrm{~s}$ in duration, and a soft tone indicated the end of the imagery processing interval. Affective picture ratings were made shortly after the imagery period. Participants were told to ignore occasional noises (the startle probes) heard on the headphones. A variable interval (12-18s) occurred between trials. Two neutral pictures served as practice trials.

\section{Physiological Data Collection and Reduction ${ }^{3}$}

The eyeblink component of the startle response was measured by recording electromyographic activity from the orbicularis oculi muscle beneath the left eye using $\mathrm{Ag} / \mathrm{AgCl}$ miniature electrodes. The raw signal was amplified by a factor of 20,000 and band-pass filtered from 90 to $1000 \mathrm{~Hz}$ using Coulbourn S75-01 bioamplifiers and then rectified and integrated with a time constant of $125 \mathrm{~ms}$. The filtered signal was sampled at $1000 \mathrm{~Hz}$, beginning $200 \mathrm{~ms}$ before startle stimulus onset and continuing until $300 \mathrm{~ms}$ after startle onset. The VPM software program was used for all aspects of stimulus timing and eyeblink data collection (Cook, 1994).

The startle responses were analyzed of line using a peak scoring algorithm developed by Globisch, Hamm, Schneider, and Vaitl (1993), which scores each trial for amplitude in arbitrary: A/D units and onset latency in milliseconds. Peak response was detected in a $20-150-\mathrm{ms}$ time window after startle stimulus onset. No effects of latency were observed, and this variable is not considered further.

The electroencephalogram (EEG) was recorded from nine sites according to the international 10-20 system using a NihonKohden amplifier and LabView software on a Macil computer. The electrodes were placed at the following leads: F3, Fz, F4, $\mathrm{C} 3, \mathrm{Cz}, \mathrm{C} 4, \mathrm{P} 3, \mathrm{Pz}$, and $\mathrm{P} 4 . \mathrm{Ag} / \mathrm{AgCl}$ electrodes were also placed on the mastoids. All channels were recorded with a $\mathrm{Cz}$ reference and converted off line to a linked-ears reference. The time constant was set at $10 \mathrm{~s}$, and the high-frequency cutoff was $35 \mathrm{~Hz}$. Vertical and horizontal eye movements were recorded using miniature $\mathrm{Ag} / \mathrm{AgCl}$ electrodes in the same frequency range as the EEG. To shorten the time lag between EEG channels during data sampling (Miller, 1990), the actual sampling rate was $1250 \mathrm{~Hz} / \mathrm{channel}$ and was converted off line to a $125-\mathrm{Hz} / \mathrm{chan}$ ne! sampling rate by discarding 9 of every 10 samples. EEG was recorded from $3 \mathrm{~s}$ before slide onset to $1 \mathrm{~s}$ after the end of the postpicture period (i.e., $16 \mathrm{~s}$ ). Separate epochs of stimulussynchronized EEG traces were extracted from the whole 16-5 EEG recording, extending from $120 \mathrm{~ms}$ before until $1 \mathrm{~s}$ after startle probe onset. All individual trials that were offiscale at any time during the 16 -s epoch were excluded from further analy-

\footnotetext{
: Measures ot heart race, skin condusiance, and corrugator musc:e were also recorded but were not retevant to the probe data and are not reported here.
} 
sis. To correct for vertical and horizontal ocular artifacts, an eye movement artifact correction (Gratton, Coles, \& Donchin, 1983; Miller, Gratton, \& Yee, 1988) was applied to single trial ERPs during picture and postpicture processing and for each valence category separately.

The P3 wave of the ERP was scored by determining the baseto-peak amplitudes on averaged waveforms for each participant, valence category, processing mode, and electrode site. Thus, nine startle trials served in the calculation of the average waveform for each valence category and processing mode. The P3 component was scored within a window beginning at N2 latency and continuing until $504 \mathrm{~ms}$. When an unequivocal positive peak could not be detected, an inflection point was calculated such that the smallest vertical distance between adjacent points within the time window defined the location for the latency of the P3, with the corresponding amplitude as the peak score. No effects of valence on the latency of the $\mathrm{P} 3$ were observed.

The N1, P2, and N2 peaks were estimated using the same method as for P3. The N1 peak was scored within a window from 64 to $192 \mathrm{~ms}$. The P2 component was scored in a time window beginning at the $\mathrm{N} 1$ latency until $272 \mathrm{~ms}$. The N2 component was scored in a window beginning at the $\mathrm{P} 2$ latency until $336 \mathrm{~ms}$.

\section{Data Analysis}

To examine affective modulation of startle reflexes during the picture processing and postpicture imagery periods, blink magnitudes were averaged and analyzed separately for each mode of processing in a repeated measures analysis of variance (ANOVA) involving the affect variable (pleasant, neutral, unpleasant). Planned tests compared all three affective categories with each other.

P3 amplitudes during both picture processing and postpicture imagery periods were analyzed separately for each mode and for the three midline and six lateral electrodes. Thus, the midline analyses contained the variables affect and location (frontal, central, parietal) and the lateral ANOVA contained the variables affect, location, and laterality (left and right hemisphere). Significant effects involving affect were followed up by comparisons among all three levels of affect.

Although the exogenous potentials were not the main object of the present study, affective modulation of these potentials appeared in the waveforms. These peaks were analyzed according to the same ANOVA format.

Effects involving repeated measures (other than those used to assess trend components) were evaluated using a multivariate test statistic (Wilks' lambda). A significance level of .05 was used in all analyses.

\section{Results}

\section{Picture Processing Period}

\section{Blink Magnitude}

Magnitude of the eyeblink responses was significantly modulated by picture pleasantness, affect $F(2.33)=7.6, p<.01$. As shown in the left panel of Figure 1, blink magnitude was larger when viewing unpleasant material than when viewing pleasant material, $F(1.34)=10.5, p<.01$, or neurral material, $F(1,34)=$ S.3. $p<.03$.

\section{Prode P:}

The grand average wavetorms of the cortical response to the siartle probes during picture processing are presented in Fig-

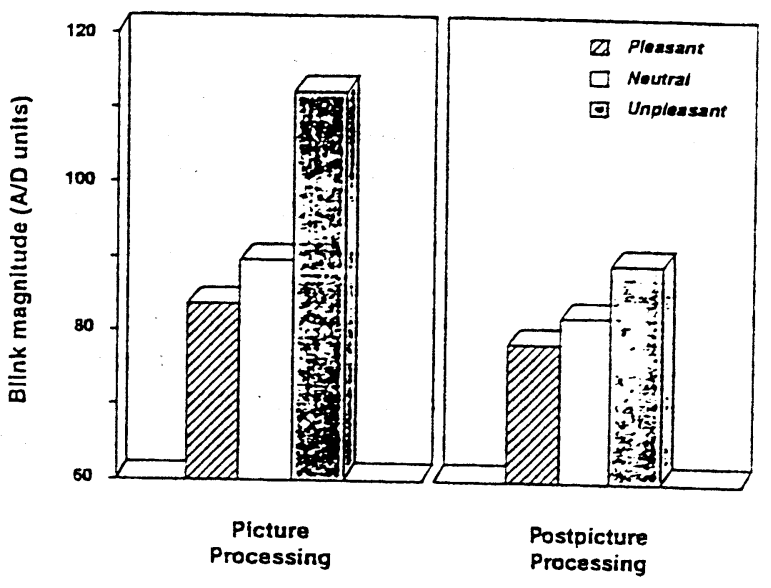

Figure 1. Blink reflexes to startle probes presented during viewing of pleasant, neutral, and unpleasant pictures (left panel) and during the postpicture processing period (right panel).

ure 2, illustrating responses in the context of each valence caregory separately for each electrode. The major finding in this study was an attenuated $\mathrm{P} 3$ amplitude when the startle probe was delivered in the context of either pleasant or unpleasant pictures as compared with neutral pictures, suggesting covariation with the arousal dimension of emotion.

Midline analyses. Analysis of midline $\mathrm{P} 3$ amplitudes resulte 2 in significant results for affect, $F(2,33)=8.7, p<.001$, and locetion, $F(2,33)=20.5, p<.0001$. Followup comparisons indicated attenuated $\mathrm{P} 3$ probe amplitudes when viewing pleasant and unpleasant as compared with neutral contents, $F(1,34)=17.2$ and $8.9, p s<.01$, respectively, but $\mathrm{P} 3$ amplitudes to probes presented during pleasant and unpleasant pictures did not differ. Probe $\mathrm{P} 3$ amplitades were also larger at $\mathrm{Pz}$ and $\mathrm{Cz}$ than at $\mathrm{Fz}$. $F(1,34)=33.9$ and $24.2, p s<.0001$, respectively. However, the Affect $\times$ Location interaction was not significant, $F(4,31)=1.3$, ns.

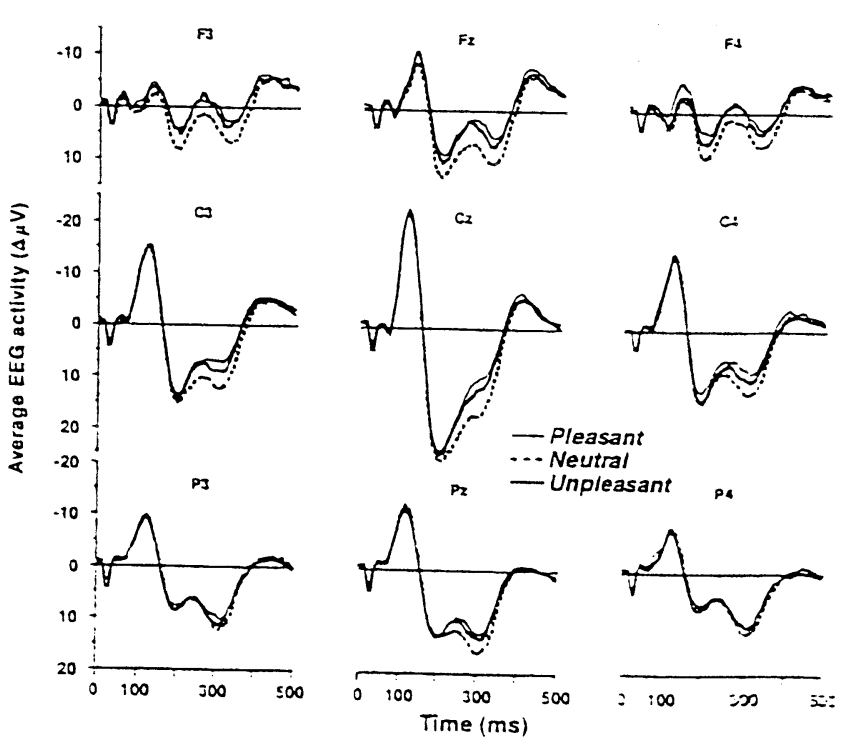

Figure 2. Startle proce synchronized grand average wavetorm: for ::= electrode sites during piciure processing presented secarate: $\because$ Or ez:valence category (pieasant, neutral. and unpieasarn). 
Lateral analyses. Overail, similar modulation with respect to affective arousal was observed for lateral leads, affect $F(2,33)=$ $9.8, p<.0001$. However, this effect interacted with location and laterality. The Affect $\times$ Location interaction, $F(4,31)=5.8$, $p<.001$, was followed by separate ANOVAs for frontal, central, and parietal leads. As shown in Table 1, affective modulation was significant at frontal and central lateral sites and was marginal at parietal sites. The Affect $\times$ Laterality interaction, $F(2,33)=4.3, p<.03$, was followed by separate ANOVAs for responses measured over the left and right hemispheres. As also shown in Table 1, both left and right hemispheric sites revealed attenuated P3 amplitudes for probes presented during pleasant and unpleasant compared with neutral pictures. In addition, the left hemisphere showed a tendency for even smaller P3s to pleasant than to unpleasant foregrounds.

As for midline electrodes, parietal and central P3 amplitudes were larger than frontal P3s, $F(1,34)=53$ and $77, p s<.0001$, location $F(2,33)=40.5, p<.0001$.

\section{$P 2$ and $N 2^{4}$}

Midline analyses. A general shift toward less positivity in the $\mathrm{P} 2$ and $\mathrm{N} 2$ area for affective as compared with neutral material resulted in significant main effects of affect, $F(2,33)>4.8$ and $3.9, p s<.03$, respectively. $\mathrm{P} 2$ amplitudes were larger for neutral than for pleasant and unpleasant material, $F(1,34)>8.9$ and $5.2, p s<.03$, respectively, and $\mathrm{N} 2$ amplitudes were more pronounced for pleasant and unpleasant as compared with neutral foregrounds, $F(1,34)=7.1$ and $6.9, p s<.02$, respectively.

Also, $\mathrm{P} 2$ amplitudes were larger at $\mathrm{Cz}$ than at $\mathrm{Fz}$ and $\mathrm{Pz}$, $F(1,34)=33.2$ and 71.0 , location $F(2,33)=35.4$, ps $<.0001$. $\mathrm{N} 2$ amplitudes were largest at $\mathrm{Fz}$, intermediate at $\mathrm{Cz}$, and smallest at $\mathrm{Pz}, F_{\mathrm{s}}(1,34)>12.2$, location $F(2,33)=18.3$, $p \mathrm{~s}<.001$.

Lateral analyses. Analyses of N2 and P2 were comparable to the lateral $\mathrm{P} 3$ results. Modulation of $\mathrm{P} 2$ and $\mathrm{N} 2$ was observed only at frontocentral leads, Affect $\times$ Location, $F(2,33)=2.5$, $p=.05$, and $F(2,33)=8.4, p<.001$, respectively. Frontally, pleasant and unpleasant contents differed from neutral for both $\mathrm{P} 2$ and $\mathrm{N} 2, F_{\mathrm{s}}(1,34)>4.7$, ps $<.04$, affect $F_{\mathrm{s}}(2,33)>6.7$, $p \mathrm{~s}<.01$. Centrally, an ordering of more positivity for neutral $>$ unpleasant $>$ pleasant foregrounds was obtained; all three contents differed for both $\mathrm{P} 2$ and $\mathrm{N} 2, F \mathrm{~s}(1,34)>4.7, p<.04$, affect $F(2,33)>3.8, p<.03$, with the single exception of the $\mathrm{P} 2$ unpleasant-neutral comparison.

For P2 only, a significant Affect $\times$ Laterality interaction occurred, $F(2,33)=3.5, p<.05$. Left hemisphere results matched the midline resuits, $F_{S}(1,34)>7.6, p<.01$, affect $F(2,33)=6.7, p<.01$. Although the right hemisphere was ordered neutral $>$ unpleasant $>$ pleasant, only the difference between pleasant and the two other categories reached signifi-

${ }^{4}$ The $\mathrm{N} 1$ peak showed no significant effect involving affect for the postpiciure period and the midline analyses during the picture period. However. the analyses of the lateral leads during picture processing revealed significant interactions of Affect $\times$ Lucation. $F(2.33)=2.6$. $p=.05$, and Affect $\times$ Laterality, $F(2.33)=3.5 . p<.05$. Both interactions were tollowed up. and the results suggested single electrode analvses of $F 3 . F 4 . C 4$. and $P 4$. Oniy F 4 revealed affectrve modulation. with a larger $V 1$ peak during unpleasant than during pieasant and neutral piciures. $F(1.3+1>10.1 . p<.01$. affes: $F(2.33)=7.9, p<.01$. This finding might suggest some laterality in alfecute processing. The result was however unpredicted. and interpretation awaits replication in subsequent research.
Table 1. Followup ANOVAs and Planned Contrasts of the Significant Interactions of Affect $\times$ Location, $F(4,31)=5.8$, $p<.001$, and Affect $\times$ Laterality, $F(2,33)=4.3, p<.03$

\begin{tabular}{|c|c|c|c|c|}
\hline $\begin{array}{l}\text { Electrode } \\
\text { sites }\end{array}$ & $\begin{array}{l}\text { Affect } \\
\text { main } \\
\text { effect }\end{array}$ & $\begin{array}{l}\text { Pleasant } \\
\text { vs. } \\
\text { unpleasant }\end{array}$ & $\begin{array}{c}\text { Pleasant } \\
\text { vs. } \\
\text { neutral }\end{array}$ & $\begin{array}{c}\text { Unpleasant } \\
\text { vs. } \\
\text { neutral }\end{array}$ \\
\hline Frontal & $7.2^{\mathrm{a}}$ & $<1$ & $14.8^{\mathrm{a}}$ & $5.3^{b}$ \\
\hline Central & $12.2^{\mathrm{a}}$ & $3.2^{c}$ & $23.3^{\mathrm{a}}$ & $8.9^{a}$ \\
\hline Parietal & 1.5 & 1.0 & 1.4 & $3.0^{c}$ \\
\hline Left & $10.2^{2}$ & $3.6^{\mathrm{c}}$ & $20.4^{a}$ & $7.5^{a}$ \\
\hline Right & $7.1^{2}$ & $<1$ & $12.7^{\mathrm{a}}$ & $5.1^{b}$ \\
\hline
\end{tabular}

Note: Letters indicate the levels of significance: $\mathrm{a}=p<.01, \mathrm{~b}=p<$ $.05, \mathrm{c}=p<.1$.

cance, $F \mathrm{~s}(1,34)>6.0, p s<.01$, affect $F(2,33)=4.1, p<.03$. Location effects were similar to those of the midline.

\section{Postpicture Imagery Period}

\section{Blink Magnitude}

Similar to the modulatory effects of pleasantness on blink magnitude during picture viewing (see Figure 1), blink responses observed in the context of imagining unpleasant were larger than those for pleasant pictures, $F(1,34)=5.8, p=.02$, although the overall main effect was slightly weaker, affect $F(2,33)=2.9$, $p=.07$.

\section{Probe P3}

Figure 3 illustrates responses to the startle stimuli during the postpicture imagery period separately for $\mathrm{Fz}, \mathrm{Cz}$, and $\mathrm{Pz}$ and the valence categories. A modulation of the probe $\mathrm{P} 3$ during the imagery period was similar to that seen during the pictureviewing period. ${ }^{5}$ An àttenuated $\mathrm{P} 3$ amplitude was recorded when the probe was presented during imagery of pleasant or unpleasant pictures compared with imagery of neutral stimuli, $F(1,34)=8.7$ and $11.9, p<.01$, affect $F(2,33)=6.4, p<.01$. Also, $\mathrm{P} 3$ amplitudes were larger at $\mathrm{Cz}$ and $\mathrm{Pz}$ than at $\mathrm{Fz}$, $F \mathrm{~S}(1,34)=45.0$ and $28.7, p s<.0001$, location $F(2,33)=26.1$, $p<.0001$.

The analyses of the lateral electrodes confirmed the midline analyses, affect $F(2,33)=5.2, p<.02$, and location $F(2,33)=$ $28.2, p<.0001$. Probes presented during pleasant and unpleasant images elicited an attenuated P3 amplitude as compared with probes presented during neutral contents, $F(1,34)=4.3$ and $10.7, p<.05$. However, affective modulation did not interact with location or laterality.

\section{$P 2$ and $N 2$ Peaks}

No significant effects involving affect were observed for the $\mathrm{N} 2$ and $\mathrm{P} 2$ peaks in the midline or lateral analyses.

\section{Discussion}

Modulation of two concurrent responses elicited by the same acoustic startle probe - the blink retlex and the P3 wave-varied

An ANOVA containing arfect. mid!ine electrodes, and mode ( pro ture and postpicture period) indicated no eifects involving mode (ail $\left.F_{S}<2, n s\right)$. 

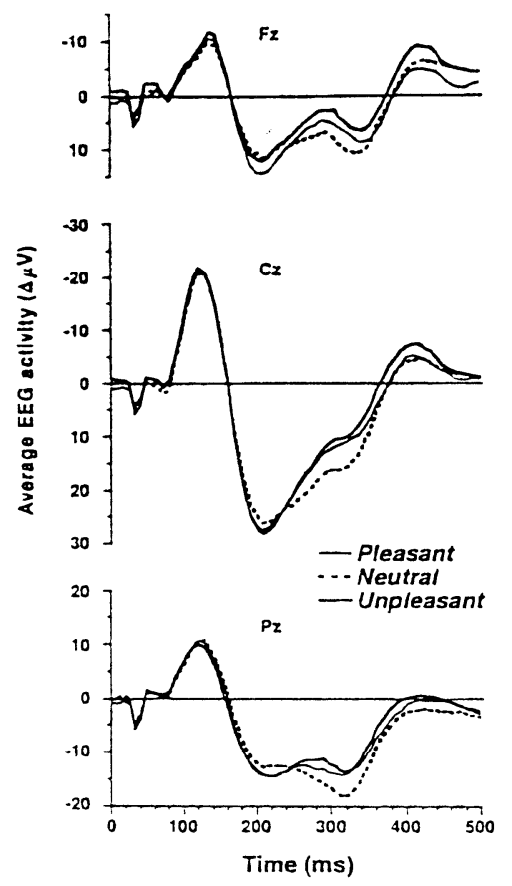

Figure 3. Grand average ERP waveforms for $\mathrm{Fz}, \mathrm{Cz}$, and Pz electrodes during the postpicture period shown separately for each valence category (pleasant, neutral, and unpleasant).

with different dimensions of emotion. As expected, blink reflexes were augmented during unpleasant as compared with pleasant pictures, replicating previous findings of a relationship between pleasantness and blink magnitude in the picture paradigm (e.g., Lang et al., 1990; Lang, Bradley, \& Cuthbert, in press). The large $\mathrm{P} 3$ wave elicited by the startle probe was differently modulated; $\mathrm{P} 3$ amplitude was reduced during processing of the more arousing emotional pictures - both pleasant and unpleasant-compared with neutral stimuli.

\section{Arousal, Attentional Engagement, and the P3 Wave}

Following theorists such as Konorski (1967) and Dickinson and Dearing (1979), we have postulated that emotion involves two systems of appetitive and defensive motivation, which organize behaviors associated with positively reinforcing (pleasant) and aversively reinforcing (unpleasant) environmental events, respectively. Arousal is not considered a separate substrate but rather represents activation in either system (Lang et al., 1990, in press; see also Cacioppo \& Berntson, 1994). At extreme arousal levels, the organism is highly mobilized to engage in appropriate actions of approach or withdrawal. Compared with neutral stimuli, pictures that are rated highly pleasant or highly unpleasant tend to be rated as higher in arousal as well (Lang et al., 1993). Further, affective modulation of the blink retlex is strongest for highly arousing pictures (Cuthbert et al., in press). The arousal dimension thus appears to index the mobilization of resources in affective engagement, regardless of whether the current motivational direcion is towards (appetitive) or away from (aversive) stimulation.

If arousal is considered an index of motivational mobiiliza:ton. it is tikety that processes of attention and selection are called upon to aciitate and serve related processing demands. Recently, we have specuiated that in the natural environment attention is primarily determined by the motivational significance of stimulus events (Lang et al., in press): People orient and attend to cues of danger and threat and to those relevant to fulfilling appetitive desires for food, sex, nurturance, and other social needs. Picture stimuli that engender activation reflect these motivational imperatives and thus prompt increased attention. Attenuation of the P3 component of the evoked starthe response is a logical consequence of allocating more attentional resources to these motivationally pertinent stimuli.

Consistent with the above view, other measures of interest in and attention to pictures also vary with increases in affective arousal. For example, emotional pictures are rated as more interesting (Lang et al., 1993) and more complex (Bradley, Greenwald, \& Hamm, 1993b) than neutral pictures and are voluntarily viewed longer in a free viewing period (Lang et al., 1993). Affective material elicits more cortical positivity at perceptual encoding than do neutral pictures (Cuthbert, Bradley, \& Lang, 1993; Palomba, 1993) and is also remembered better (Bradley et al., 1993; Bradley, Greenwald, Petry, \& Lang, 1992). Importantly, when processing emotional pictures, individuals are slower to respond to a secondary reaction time probe than when viewing neutral pictures (Bradley \& Lang, in press), consistent with the idea that arousing stimuli draw more attentional resources at encoding.

This hypothesis is also consistent with data and theory from ERP studies that suggest that $\mathrm{P} 3$ amplitude varies with attentional variables (e.g., Donchin \& Coles, 1988; Picton, 1992). A larger P3 wave commonly is obtained when a stimulus is given enhanced attention by making it task relevant. That is, a stimulus that generates a large $\mathrm{P} 3$ when associated with a task fails to elicit a P3 when this same stimulus is unattended or ignored (reviewed by Donchin \& Coles, 1988). Importantly, a number of dual-task studies have found a reduced $\mathrm{P} 3$ wave to a target stimulus in a secondary (oddball) task when attention was directed to a primary task in the visual modality (Donchin, Kramer, \& Wickens, 1986). For instance, Isreal, Chesney, Wickens, and Donchin (1980) found that increasing the perceptual difficulty of a primary visual task resulted in attenuated secondary P3 amplitudes. A study by Polich (1989) revealed similar attentional modulation even when no explicit task was associated with the secondary probe task. Roth et ai. (1984) used a passive startle probe instead of an oddball as secondary task and also reported attenuation of the probe $\mathrm{P} 3$ in the presence of a visual foreground task.

It therefore seems reasonable to hypothesize that the probe $\mathrm{P} 3$ is modulated by arousing, emotional stimuli in a way similar to that seen in other studies requiring an allocation of resources to visual attention. In the present experiment, however, attentional set was not manipulated by instruction or varying task requirements; attention was determined by the intrinsic motivational significance of the picture stimuli.

\section{Processing Mode and ERP Modulation}

Affective modulation of the blink retlex and arousal modulation of the $\mathrm{P} 3$ response persisted into the postpicture imagery period, after actual viewing of the perceptual stimulus had ceased. Thus, subsequent cognitive processing of an emotionai content apparently has effects simiiar to those found in ac:ual picture perception. Although the particular instruction given in the postpicture imagery period was not expiicirly varied in this study, recent dara (Cuthbert et al., 1995) suggest that these mod- 
ulatory effects rely on an instruction to maintain a mental image of the just-presented picture and are not found in a postpicture interval in the absence of such an instruction (see also Bradley, Cuthbert, \& Lang, 1993a).

In contrast to the data obtained for P3, effects for earlier ERP components (i.e., greater negativity at N2 and P2 for emotional pictures) were not observed in the postprocessing imagery period. In fact, the differences between arousing and neutral images after picture viewing were somewhat in the opposite direction, that is, greater positivity with arousal, as shown in Figure 3. Thus, like $\mathrm{P} 3$, the eariy components appear to discriminate between emotional and neutral pictures; unlike $\mathrm{P} 3$, however, this early effect appears to be dependent on the presence of the physical stimulus.
Two measures of the same startle response, the reflexive a:eblink and the event-related potential, are differentially modified by the parameters of affective valence (pleasure) and affective arousal, respectively. Blinks modulated by the pleasure dimension may reflect motivational priming; P3s modulated by affective arousal may index associated mobilization of attentional and metabolic resources. These modulatory effects may depend on parameters of the current paradigm, in which the individual is passively perceiving a foreground stimulus and is explicitly told to ignore the secondary startle probes. Under these circumstances, the motivational imperative of the foreground stimulus clearly dictates probe responses. Reflex and cortical measures separately index the motivational dimensions of affective valence and activation.

\section{REFERENCES}

Bradley, M. M., Cuthbert, B. N., \& Lang, P. J. (1990). Startle reflex modification: Emotion or attention? Psychophysiology, 27, 513-521.

Bradley, M. M., Cuthbert, B. N., \& Lang, P. J. (1993a). Pictures as prepulse: Attention and emotion in startle modification. Psychophysiology, 30, 541-545.

Bradley, M. M., Greenwald, M. K., \& Hamm, A. O. (1993b). Affective picture processing. In N. Birbaumer \& A. Öhman (Eds.), The structure of emotion: Psychophysiological, cognitive, and clinical aspects (pp. 48-65). Toronto: Hogrefe \& Huber.

Bradley, M. M., Greenwald, M. K., Petry, M., \& Lang, P. J. (1992). Remembering pictures: Pleasure and arousal in memory. Journal of Experimental Psychology: Learning, Memory and Cognition, 18, 379-390.

Bradley, M. M., \& Lang, P. J. (in press). Picture media and emotion: Effects of sustained affective context. Psychophysiology.

Cacioppo, J. T., \& Berntson, G. G. (1994). Relationships between attitudes and evaluative space: A critical review with emphasis on the separability of positive and negative substrates. Psychological Bulletin, 115, 401-423.

Center for the Study of Emotion and Attention [CSEA-NIMH] (1995). The international affective picture system [IAPS; photographic slides]. Gainesville, FL: University of Florida.

Cook, E. W., III. (1994). VP.M reference manual. Birmingham, AL: Author.

Cuthbert, B. N., Bradley, M. M., \& Lang, P. J. (1993). Orienting and affect: Cortex-reflex connection [Abstract]. Psychophysiology, 30(Suppl.), S7.

Cuthbert, B. N., Bradley, M. M., \& Lang, P. J. (1996). Probing picture perception: Acrivation and emotion. Psychophysiology, 33, 103-111.

Cuthbert, B. N., Schupp, H. T., McManis, M., Hillman, C., Bradley, M. M., \& Lang, P. (1995). Cortical slow waves: Emotional perception and processing [Abstract]. Psychophysiology, 32(Suppl.), S26.

Dickinson, A., \& Dearing, M. F. (1979). Appetitive-aversive interactions and inhibitory processes. In A. Dickinson \& R. A. Boakes (Eds.), . Hechanisms of learning and motivation (pp. 203-231). Hillsdale, $\mathrm{NJ}$ : Erlbaum.

Donchin, E., \& Coles, M. G. H. (1988). Is the P300 component a manifestation of context updating? Behavioral and Brain Sciences, $11(3)$, $357-27$.

Donchin, E., Kramer, A. F., \& Wickens, C. (1986). Applications of brain event-related potentials to problems in engineering psychology. In M. G. H. Coles. E. Donchin. \& S. W. Porges (Eds.), Psichophysiology - Sistems, processes, und applications (pp. 702iis). Vew York: Guilford Press.

Furd. J. M.. \& Pferferbaum. A. (1991). Event-reiated potentiais and eyeblink responses in automatic and controlled processing: Effects of aye. journat of Eiectroencephaiograpinl and Clinical Veuropinystolog!. - S. $361-37:$

Globisch. J., Hamm. A.. Schneider, R., \& Viutl. D. (1993). A computer aroyram tor scoring retlex eteblink and electrodermal responses written in Pasial (Abstraci). Pstchopitysiology, jO(Suppi.), Sjo.
Gratton, G., Coles, M. G. H., \& Donchin, E. (1983). A new method for off-line removal of ocular artifact. Journal of Electroencephalography and Clinical Neurophysiology, 55, 468-484.

Isreal, J. B., Chesney, G. L., Wickens, C. P., \& Donchin, E. (1980). P 300 and tracking difficulty: Evidence for multiple resources in dualtask performance. Psychophysiology, 17, 259-273.

Konorski, J. (1967). Integrative activity of the brain: An interdisciplinary approach. Chicago: University of Chicago Press.

Lang, P. J. (1980). Behavioral treatment and bio-behavioral assessment: Computer applications. In J. B. Sidowski, J. H. Johnson, \& T. A. Williams (Eds.), Technology in mental health care delivery (pp. 119 137). Norwood, NJ: Albex.

Lang, P. J. (1995). The emotion probe. American Psychologist, 50, $372-385$

Lang, P. J., Bradley, M. M., \& Cuthbert, B. N. (1990). Emotion, attention, and the startle reflex. Psychological Review, 97, 377-395.

Lang, P. J., Bradley, M. M., \& Cuthbert, B. N. (in press). Motivated attention: Affect, activation, and action. In P. J. Lang, R. F. Simons. \& M. Balaban (Eds.), Attention and orienting: Sensory and motivational processes. Hillsdale, NJ: Eribaum.

Lang, P. J., Greenwald, M. K., Bradley, M. M., \& Hamm, A. O. (1993). Looking at pictures: Affective, facial, visceral, and behavioral reactions. Psychophysiology, 30, 261-273.

Miller, G. A. (1990). DMA-mode timing questions for $A / D$ converters. Psychophysiology, 27, 358-359.

Miller, G. A., Gratton, G., \& Yee, C. .M. (1988). Generalized implementation of an eye movement correction procedure. Psychophysiolog. $25,241-243$.

Palomba, D. (1993). Modificazioni fisiologiche e attivita cognitive nelle emozioni. Rassegna di Psicologia. 3, 165-189.

Picton, T. W. (1992). The P300 wave of the human erent-related potential. Journal of Clinical Neuroph!siology, 9, $456-79$.

Polich, J. (1989). P300 from a passive auditory paradigm. Journal of Electroencephalography and Clinical Neurophysiology, 74, 312-320.

Putnam, L. E., \& Roth, W. T. (1990). Effects of stimulus repetition. duration, and rise time on startle blink and automatically eilicited P300. Psychophysiology, 27, 275-297.

Roth, W. T., Dorato, K. H., \& Kopell. B. S. (1984). Intensity and task effects on evoked physiological response to noise bursts. Psychophysiology, 21, 466-481.

Schupp, H.. Cuthbert. B., Bradley, M., Lang, P.. ذ Birbaumer, N (1993). Imagining the percept: Cortical and peripheral measures [Abstract]. Psycizophysiolog!; 30(Suppi.), Sis.

Sugawara. M.. Sadeghpour, M.. DeTraversay, J.. 3. Ornizz. E. M. (1994). Prestimulation-induced modulation or the P300 component of the event-related potentials acicompanying starte in children. Jour-

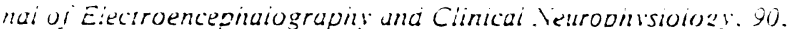
$201-2 ! 3$.

(RECEINED Aprii 11, 1995: ACCEPTED Aprii 1. 1990) 